Article

\title{
Tuning the Geometrical Structures and Optical Properties of Blue-Emitting Iridium(III) Complexes through Dimethylamine Substitutions: A Theoretical Study
}

\author{
Xue-Feng Ren ${ }^{1,2}$, Hong-Qu Tang ${ }^{1}$ and Guo-Jun Kang ${ }^{1, *}$ \\ 1 Low Carbon Energy Institute, School of Chemical Engineering \& Technology, \\ China University of Mining \&Technology, Xuzhou 221008, China; renxf@cumt.edu.cn (X.-F.R.); \\ jzhangmt@126.com (H.-Q.T.) \\ 2 Fukui Institute for Fundamental Chemistry, Kyoto University, 34-4 Takano Nishihiraki-cho, Sakyo, \\ Kyoto 606-8103, Japan \\ * Correspondence: gjkang@cumt.edu.cn; Tel.: +86-516-8388-3501
}

Academic Editor: Jwo-Huei Jou

Received: 29 March 2017; Accepted: 5 May 2017; Published: 7 May 2017

\begin{abstract}
The geometrical structures and photophysical properties of $\operatorname{Ir}(4,6-\mathrm{dFppy})_{2}$ (pic) (FIrpic) and its derivative ( $o$-FIr, $m$-FIr, $p$-FIr) with dimethylamine substituted at the picolinic acid $\left(\mathrm{N}^{\wedge} \mathrm{O}\right)$ ligand were fully investigated by density functional theory and time-dependent density functional theory. The simulated electronic structure, as well as absorption and emission spectra of FIrpic are in good agreement with the experimental observations. The introduction of dimethylamine at the $\mathrm{N}^{\wedge} \mathrm{O}$ ligand at different positions is beneficial to extend the $\pi$-electron delocalization, increase HOMO energy levels, and hence improve the hole injection and transfer ability compared with those of FIrpic. Furthermore, $o$-FIr, $m$-FIr, and $p$-FIr have large absorption intensity and participation of metal-to-ligand charge transfer (MLCT) contribution in the main absorption spectra, which would be useful to improve the intersystem crossing (ISC) from the singlet to triplet excited state. More importantly, the high quantum yield of $o$-FIr (which is explained based on the detailed analysis of triplet energy, $\mathrm{E}_{\mathrm{T} 1}$ ), participation of ${ }^{3} \mathrm{MLCT}$ contribution in the phosphorescent spectra, and energy difference between ${ }^{3} \mathrm{MLCT}$ and triplet metal centered $\left({ }^{3} \mathrm{MC}\right) \mathrm{d}$-d excited state compared with $m$-FIr and $p$-FIr indicate that $o$-FIr is expected to be an excellent blue phosphorescence emitter with high efficiency.
\end{abstract}

Keywords: DFT; dimethylamine; phosphorescence; ${ }^{3} \mathrm{MC}$ d-d excited states

\section{Introduction}

Phosphorescent transition metal materials such as $\operatorname{Re}(\mathrm{I}), \operatorname{Ru}(\mathrm{II})$, and $\operatorname{Ir}(\mathrm{III})$ complexes are of great interest [1-4], because these materials have been extensively investigated for optoelectronic and microelectronic applications, such as dye-sensitized solar cells (DSSCs) and organic light-emitting diodes (OLEDs) [5-7]. Among these emitters, $\operatorname{Ir}(4,6-\mathrm{dFppy})_{2}$ (pic) (FIrpic) is one of the most well-known blue phosphorescent emitters, which is widely used as a dopant in the electroluminescent layers of OLEDs [8-10]. However, the quantum yield and equilibrium between the hole and electron transportation of FIrpic are considered to be difficult for its further application. The development of high-performance blue-emitting materials is strongly required for the fabrication of OLEDs. Unfortunately, it is a challenging task to achieve stable and high-efficiency blue phosphorescent emitters because the blue phosphorescence complex has a high emission state compared with other 
color complexes. This enables thermal activation to triplet metal centered $\left({ }^{3} \mathrm{MC}\right) \mathrm{d}-\mathrm{d}$ state, which is one of the main nonradiative processes from the emissive excited state for $\operatorname{Ir}(\mathrm{III})$ complexes [11,12].

In OLEDs, researchers can control the emission color and photophysical properties of emitters by a modification of the chelating ligands [13-17]. The common approach in tuning the photophysical properties of FIrpic is to modify the chemical structures of 2-(2,4-difluorophenyl) pyridine $\left(\mathrm{C}^{\wedge} \mathrm{N}\right)$ ligands. Baranoff et al. [18] replaced the $\mathrm{F}$ atoms on FIrpic by $\mathrm{H}, \mathrm{Cl}$, and $\mathrm{Br}$. They found that the large halogen substituent contributed to sizable distortions of specific $\left(\mathrm{C}^{\wedge} \mathrm{N}\right)$ ligands, which were likely to play a role in the emissive and nonradiative properties when coupled with the heavy-atom effect. Owing to the introduction of the strong electron withdrawing perfluoro carbonyl group on $\left(\mathrm{C}^{\wedge} \mathrm{N}\right)$ ligands of FIrpic, the newly designed Ir complexes displayed deepest blue emissions and considerably high external quantum efficiencies (EQEs) [19]. Li et al. [20] investigated a series of $\operatorname{Ir}(\mathrm{III})$ complexes by introducing tert-butyl, $n$-heptyl, 3-ethylheptyl, and 2,4,6-trimethylphenyl substituted groups into the $\left(\mathrm{C}^{\wedge} \mathrm{N}\right)$ ligands of FIrpic. They revealed that both the substituted group and position had an effect on tuning the emission energies and quantum yield. However, the important chelating picolinic acid $\left(\mathrm{N}^{\wedge} \mathrm{O}\right)$ ligand of FIrpic has not received as much attention, to the best our knowledge. Herein, we will theoretically design and investigate a type of Ir complexes $o$-FIr, $m$-FIr, $p$-FIr (Figure 1) by introducing the dimethylamine substituted at the picolinic acid $\left(\mathrm{N}^{\wedge} \mathrm{O}\right)$ ligand, because the dimethylamine is one of the most popular functional groups used as hole transfer materials. We perform detailed theoretical calculations on the electronic structure, absorption and emission properties, quantum efficiency, as well as charge transport properties, aiming at revealing the relationship between the structures and photophysical properties. This work is expected to give some insights into the design and synthesis of blue emitters with high quantum efficiency.
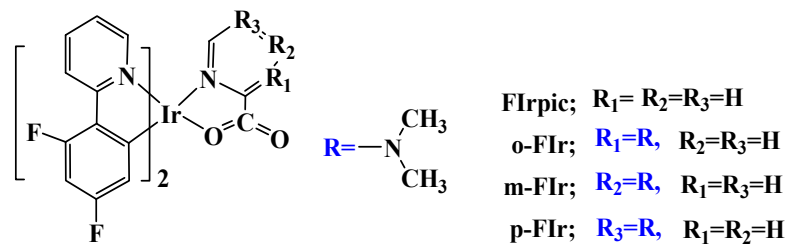

Figure 1. Schematic structures of the studied complexes.

\section{Results and Discussion}

\subsection{The Optimized Geometries in the Ground and Lowest Lying Triplet Excited States}

The schematic structures of FIrpic, $o$-FIr, $m$-FIr, and $p$-FIr are depicted in Figure 1. The ground-state $\left(\mathrm{S}_{0}\right)$ geometry of FIrpic was optimized by B3LYP, CAMB3LYP, M06L, MPW1PW91 functionals with the same basis set. The detailed geometries and available crystal data of FIrpic [21] are collected in Table S1 in supporting information. It is found that M06L functional predicts more satisfied geometrical structures by compared with the experimental data. Therefore, the $\mathrm{S}_{0}$ geometries of $o$-FIr, $m$-FIr, $p$-FIr are calculated by M06L functional, and the optimized geometries as well as the numbering of some key atoms are depicted in Figure 2. The optimized primary metal-ligand bond lengths of these designed complexes in the ground-state $\left(\mathrm{S}_{0}\right)$ geometry are collected in Table 1.

As listed in Table 1, the $\mathrm{N}_{1}-\mathrm{Ir}-\mathrm{N}_{2}$ and $\mathrm{O}_{1}-\mathrm{Ir}-\mathrm{N}_{2}$ of FIrpic are ca. $90^{\circ}$, and the dihedral angle of $\mathrm{N}_{1}-\mathrm{O}_{1}-\mathrm{C}_{2}-\mathrm{C}_{1}$ of FIrpic is $6.8^{\circ}$. Obviously, FIrpic has distorted octahedral geometry around the $\operatorname{Ir}(\mathrm{III})$ atom. Table 1 shows that the $\mathrm{N}_{1}-\mathrm{Ir}-\mathrm{N}_{2}, \mathrm{O}_{1}-\mathrm{Ir}-\mathrm{N}_{2}$, and $\mathrm{N}_{1}-\mathrm{O}_{1}-\mathrm{C}_{2}-\mathrm{C}_{1}$ of $o$-FIr, $m$-FIr, and $p$-FIr are similar to those of FIrpic. Clearly, the introduction of a dimethylamine moiety on the pyridine moiety of picolinic acid $\left(\mathrm{N}^{\wedge} \mathrm{O}\right)$ does not affect the distorted octahedral geometry of the $\operatorname{Ir}(\mathrm{III})$ complex. For $o$-FIr and $p$-FIr, because of the introduction of dimethylamine group on the pyridine, the Ir- $\mathrm{N}_{1}$ and Ir- $\mathrm{O}_{1}$ of $o$-FIr and $p$-FIr are shortened $(0.005 \AA$ and $0.01 \AA$ for $o$-FIr, while $0.05 \AA$ and $0.016 \AA$ for $p$-FIr) in comparison to those of FIrpic. These calculated results indicate that there is a strong interaction 
between the $\operatorname{Ir}(\mathrm{III})$ and $\left(\mathrm{N}^{\wedge} \mathrm{O}\right)$ ligand. Furthermore, the $\operatorname{Ir}-\mathrm{N}_{1}$ bond length of $o$-FIr, $m$-FIr, and $p$-FIr are significantly shortened compared with that of FIrpic; therefore, the possible of dissociation of Ir- $\mathrm{N}_{1}$ bond in the ${ }^{3} \mathrm{MC}$ state is expected to be decreased by the incorporation of $\mathrm{N}\left(\mathrm{CH}_{3}\right)_{2}$ groups.

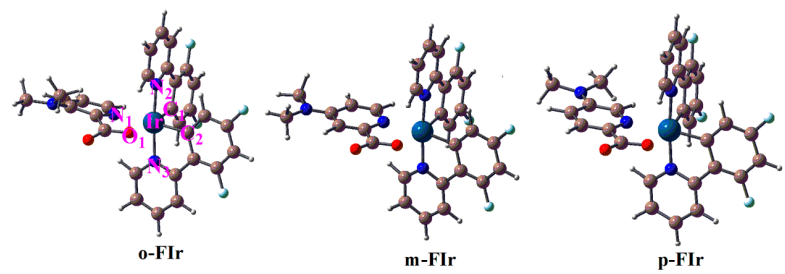

Figure 2. Optimized structures of $o$-FIr, $m$-FIr, and $p$-FIr in the ground state, together with the number of some key atoms.

Table 1. Calculated metal-ligand bond lengths $(\AA)$, bond angles $\left(^{\circ}\right)$, and dihedral angles $\left(^{\circ}\right)$ for studied complexes in the ground state $\left(\mathrm{S}_{0}\right)$ and first excited triplet state $\left(\mathrm{T}_{1}\right)$.

\begin{tabular}{|c|c|c|c|c|c|c|c|c|c|c|}
\hline Molecule & State & Ir-N 1 & Ir-O $\mathrm{O}_{1}$ & Ir- $\mathbf{N}_{2}$ & $\operatorname{Ir}-\mathrm{C}_{1}$ & Ir- $\mathrm{N}_{3}$ & $\mathrm{Ir}-\mathrm{C}_{2}$ & $\mathrm{~N}_{1}-\mathrm{Ir}-\mathrm{N}_{2}$ & $\mathrm{O}_{1}-\mathrm{Ir}-\mathrm{N}_{2}$ & $\mathrm{~N}_{1}-\mathrm{O}_{1}-\mathrm{C}_{2}-\mathrm{C}_{1}$ \\
\hline \multirow{2}{*}{ FIrpic } & $\mathrm{S}_{0}$ & 2.215 & 2.190 & 2.066 & 2.001 & 2.058 & 1.997 & 88.4 & 93.5 & 6.8 \\
\hline & $\mathrm{T}_{1}$ & 2.313 & 2.172 & 2.069 & 1.979 & 2.060 & 1.975 & 97.1 & 88.7 & -3.4 \\
\hline \multirow{2}{*}{$o$-FIr } & $\mathrm{S}_{0}$ & 2.210 & 2.180 & 2.066 & 2.002 & 2.054 & 1.997 & 87.3 & 94.0 & 5.0 \\
\hline & $\mathrm{T}_{1}$ & 2.316 & 2.154 & 2.057 & 1.981 & 2.067 & 1.977 & 84.4 & 93.7 & 3.1 \\
\hline \multirow{2}{*}{$m$-FIr } & $\mathrm{S}_{0}$ & 2.206 & 2.193 & 2.064 & 2.002 & 2.056 & 1.995 & 88.6 & 93.0 & 7.2 \\
\hline & $\mathrm{T}_{1}$ & 2.285 & 2.171 & 2.069 & 1.979 & 2.057 & 1.978 & 95.9 & 89.0 & -4.6 \\
\hline \multirow{2}{*}{$p$-FIr } & $\mathrm{S}_{0}$ & 2.165 & 2.177 & 2.055 & 2.010 & 2.045 & 2.001 & 87.6 & 92.9 & 6.3 \\
\hline & $\mathrm{T}_{1}$ & 2.305 & 2.160 & 2.068 & 1.982 & 2.058 & 1.977 & 97.4 & 88.7 & -3.0 \\
\hline
\end{tabular}

The lowest lying triplet excited states $\left(\mathrm{T}_{1}\right)$ of studied complexes are also listed in Table 1. As listed in Table 1 , the Ir- $\mathrm{N}_{1}$ bond length of these complexes is dramatically elongated in the $\mathrm{T}_{1}$ state in comparison with that in $\mathrm{S}_{0}$ state. This suggests that the interaction between the $\mathrm{N}^{\wedge} \mathrm{O}$ ligand and the metal is weakened in the $T_{1}$ state. From the $S_{0}$ to the $T_{1}$ state, the $\operatorname{Ir}-C_{1 / 2}$ and $\operatorname{Ir}-\mathrm{N}_{2 / 3}$ bond lengths of 2-(2,4-difluorophenyl)pyridine $\left(\mathrm{C}^{\wedge} \mathrm{N}\right)$ ligands in $o$-FIr, $m$-FIr, and $p$-FIr are contracted by the substitutions of the dimethylamine groups on the pyridine moiety. The strengthened metal-ligand bonds will strength the interaction between the metal and $\mathrm{C}^{\wedge} \mathrm{N}$ ligands and further benefit the charge transfer from the metal to ligand, which may improve the quantum efficiency.

\subsection{Froniter Molecular Orbtials}

Considering that frontier molecular orbitals are useful to provide the nature of the charge transfer and photophysical properties in the excited state, the HOMO and LUMO energies, HOMO-LUMO energy gaps, and the contour plots of these orbitals of studied complexes are drawn in Figure 3. Detailed descriptions of the frontier molecular compositions are collected in Table S2 in the supporting information.

Normally, when the interfacial vacuum energy shift can be neglected, the hole (or electron) injection energy barrier from the electrode to semiconductor $\left(\Phi_{\mathrm{h}}\right)$ (or $\Phi_{\mathrm{e}}$ ) can be calculated by $\Phi_{\mathrm{h}}=|\mathrm{HOMO}|-\Phi_{\mathrm{m}}\left(\right.$ or $\left.\Phi_{\mathrm{e}}=\Phi_{\mathrm{m}}-|\mathrm{LUMO}|\right)$, where $\Phi_{\mathrm{m}}$ is the work function of the electrode [22] Consider that $\mathrm{Au}\left(\Phi_{\mathrm{m}}=5.1 \mathrm{eV}\right)$ is widely used as electrode in OLEDs; therefore, it is used as reference electrode [22]. As depicted in Figure 3, the HOMO and LUMO energies of $o$-FIr, $p$-FIr, and $m$-FIr increase remarkably $(-4.65 \mathrm{eV}$ and $-2.15 \mathrm{eV}$ for $o$-FIr, $-4.59 \mathrm{eV}$ and $-2.07 \mathrm{eV}$ for $m$-FIr, $-4.65 \mathrm{eV}$ and $-2.16 \mathrm{eV}$ for $p$-FIr) compared with FIrpic $(-4.80 \mathrm{eV}$ and $-2.30 \mathrm{eV})$. Therefore, the calculated $\Phi_{\mathrm{h}}$ of these complexes are (in the region of $0.30-0.51 \mathrm{eV}$ ) much smaller than those of the calculated $\Phi_{\mathrm{h}}$ values (in the region of 2.80-3.03 eV). It is obvious that these emitters are suitable for use as p-type organic semiconductors [23]. Furthermore, the HOMO energy level of $o$-FIr $(0.15 \mathrm{eV}), m$-FIr $(0.21 \mathrm{eV})$, and 
p-FIr $(0.15 \mathrm{eV})$ is significantly higher than that of FIrpic. The higher HOMO energies will benefit the hole injection abilities. Together with the increasing HOMO and LUMO energy, the HOMO-LUMO energy gaps of our designed molecules are similar to that of FIrpic, which means that absorption and phosphorescent spectra of these designed complexes might be similar to that of FIrpic when these spectra are predominantly contributed by the $\mathrm{HOMO} \rightarrow$ LUMO transition.

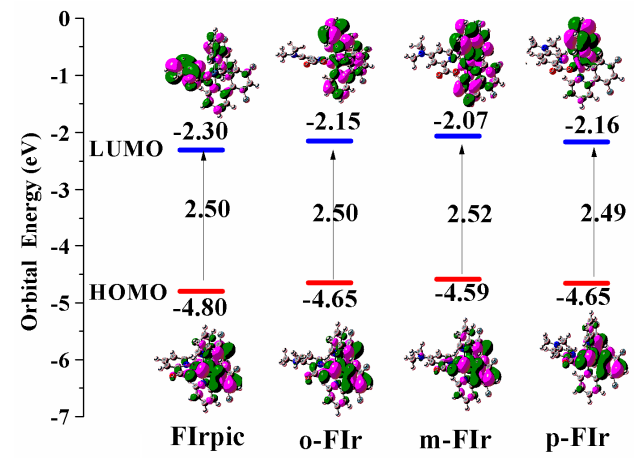

Figure 3. The orbital energies and contour plot of the HOMO and LUMO of studied complexes.

For FIrpic, $o$-FIr, $p$-FIr, and $m$-FIr, the electron densities of HOMOs are mainly located on $50 \% \mathrm{~d}(\mathrm{Ir})$ orbital and $38 \% \pi\left(\mathrm{C}^{\wedge} \mathrm{N}\right.$ ligands) orbital, as shown in Figure 3 and Table S2. Owing to the introduction of $\mathrm{N}\left(\mathrm{CH}_{3}\right)_{2}$ groups, the LUMOs in $o$-FIr, $m$-FIr, and $p$-FIr are mainly focused on the $\mathrm{C}^{\wedge} \mathrm{N}$ ligands with about $90 \%$ compositions, while the LUMO in FIrpic is contributed by $\mathrm{N}^{\wedge} \mathrm{O}$ ligand. The HOMO- 1 of these studied complexes is mainly focused on the ca. $50 \% \mathrm{~d}$ orbital the ca. $30 \% \pi$ orbitals of $\mathrm{N}^{\wedge} \mathrm{O}$ ligand, while theirs HOMO-2 are mainly contributed by $\mathrm{N}^{\wedge} \mathrm{O}$ ligand. The contributions of $\mathrm{d}(\mathrm{Ir})$ orbital on HOMO-3 of $o$-FIr (67.5\%) and $m$-FIr (56.9\%) are similar to that of FIrpic (67.1\%). This means that the $\mathrm{N}\left(\mathrm{CH}_{3}\right)_{2}$ substitutions have a minor effect on the composition of the frontier molecular orbital. Therefore, the nature of electron transition upon excitations of $o$-FIr, $p$-FIr, and $m$-FIr might be similar with those of FIrpic, which will be further investigated in the following section.

\subsection{Absorption Spectra}

The calculated absorption spectra of studied complexes associated with oscillator strengths (f) and the corresponding compositions, as well as the experimental data [24] are given in Table 2. Simulated absorption spectra of these complexes with the data calculated at the TD-M06L method are drawn in Figure 4.

As listed in Table 2, the main calculated values of these bands are localized at 453.00, 380.95, and $265.86 \mathrm{~nm}$ for FIrpic, respectively, which are in good agreement with the experimental results of 458, 379 , and $256 \mathrm{~nm}$, respectively [24]. For the low-lying absorption spectra of FIrpic, the excitations of $\mathrm{HOMO} \rightarrow \mathrm{LUMO}+1$ and $\mathrm{HOMO}-1 \rightarrow \mathrm{LUMO}+2$ are dominantly responsible for the absorption peaks at 453.00 and $380.95 \mathrm{~nm}$, respectively. As listed in Table S2, the HOMO and HOMO - 1 are delocalized on the $\operatorname{Ir}(\mathrm{d}), \mathrm{N}^{\wedge} \mathrm{O}$, and $\mathrm{N}^{\wedge} \mathrm{C}$ ligand, while the $\mathrm{LUMO}+1$ and $\mathrm{LUMO}+2$ are mainly contributed by the $\mathrm{N}^{\wedge} \mathrm{C}$ ligand. Therefore, from the analysis of FMOs, the absorption peaks at 453.00 and $380.95 \mathrm{~nm}$ can be characterized as metal-to-ligand charge transfer (MLCT), inter-ligand charge transfer (ILCT), and ligand-ligand charge transfer (LLCT). The absorption peak with largest oscillator strength $(f=0.2104)$ of FIrpic is located at $265.86 \mathrm{~nm}$, which is arising from the $\mathrm{HOMO}-8 \rightarrow \mathrm{LUMO}+$ 2 and $\mathrm{HOMO} \rightarrow \mathrm{LUMO}+7$ transitions. Because of the large of amount of $\operatorname{Ir}(\mathrm{d})$ in $\mathrm{HOMO}(50.7 \%)$ and HOMO - 8 (20.8\%), the absorption peak at $265.86 \mathrm{~nm}$ can mainly be assigned to the MLCT/LLCT/ILCT character. From the analysis of frontier molecule orbital compositions, the mount of MLCT of the 453.00, 380.95, and 265.86 for FIrpic is $21.07 \%, 21.07 \%$, and 7.16\%, respectively. The significant MLCT contributions on the lower-lying absorptions of FIrpic are in good agreement with the experimental results [24]. 
Table 2. The calculated maximum absorption wavelength $(\mathrm{nm})$, oscillator strengths $(f)$, and major contribution transition composition for studied complexes obtained by TD-M06L method. FIrpic: $\operatorname{Ir}(4,6-\mathrm{dFppy})_{2}$ (pic).

\begin{tabular}{|c|c|c|c|c|c|c|}
\hline Molecule & Transition & $\lambda(\mathrm{nm})$ & $f$ & Composition & CI & Exp. [24] (nm) \\
\hline \multirow{3}{*}{ FIrpic } & $\mathrm{S}_{0} \rightarrow \mathrm{S}_{2}$ & 453.00 & 0.0250 & $\mathrm{HOMO} \rightarrow \mathrm{LUMO}+1$ & 0.68971 & 455 \\
\hline & $\mathrm{S}_{0} \rightarrow \mathrm{S}_{7}$ & 380.95 & 0.0614 & $\mathrm{HOMO}-1 \rightarrow \mathrm{LUMO}+2$ & 0.55936 & 379 \\
\hline & $\mathrm{S}_{0} \rightarrow \mathrm{S}_{50}$ & 265.86 & 0.2104 & $\begin{array}{c}\mathrm{HOMO}-8 \rightarrow \mathrm{LUMO}+2 \\
\mathrm{HOMO} \rightarrow \mathrm{LUMO}+7\end{array}$ & $\begin{array}{l}0.38300 \\
0.24359\end{array}$ & 256 \\
\hline \multirow{8}{*}{$o$-FIr } & $\mathrm{S}_{0} \rightarrow \mathrm{S}_{1}$ & 463.87 & 0.0258 & $\mathrm{HOMO} \rightarrow \mathrm{LUMO}$ & 0.70168 & \\
\hline & $\mathrm{S}_{0} \rightarrow \mathrm{S}_{7}$ & 395.15 & 0.0266 & $\begin{array}{l}\mathrm{HOMO}-2 \rightarrow \mathrm{LUMO}+2 \\
\mathrm{HOMO}-1 \rightarrow \mathrm{LUMO}+2\end{array}$ & $\begin{array}{l}0.56244 \\
-0.40890\end{array}$ & \\
\hline & $\mathrm{S}_{0} \rightarrow \mathrm{S}_{52}$ & 269.04 & 0.1135 & $\begin{array}{l}\mathrm{HOMO}-9 \rightarrow \mathrm{LUMO}+1 \\
\mathrm{HOMO}-5 \rightarrow \mathrm{LUMO}+5 \\
\mathrm{HOMO}-1 \rightarrow \mathrm{LUMO}+7\end{array}$ & $\begin{array}{l}0.25480 \\
0.42176 \\
0.23321\end{array}$ & \\
\hline & $\mathrm{S}_{0} \rightarrow \mathrm{S}_{53}$ & 268.66 & 0.1642 & $\begin{array}{l}\mathrm{HOMO}-7 \rightarrow \mathrm{LUMO}+4 \\
\mathrm{HOMO}-1 \rightarrow \mathrm{LUMO}+7\end{array}$ & $\begin{array}{l}-0.35667 \\
0.36355\end{array}$ & \\
\hline & $\mathrm{S}_{0} \rightarrow \mathrm{S}_{54}$ & 266.76 & 0.1318 & $\begin{array}{c}\mathrm{HOMO}-9 \rightarrow \mathrm{LUMO}+2 \\
\mathrm{HOMO}-2 \rightarrow \mathrm{LUMO}+7 \\
\mathrm{HOMO}-1 \rightarrow \mathrm{LUMO}+7 \\
\mathrm{HOMO} \rightarrow \mathrm{LUMO}+7\end{array}$ & $\begin{array}{l}0.21920 \\
0.26962 \\
-0.21838 \\
0.41903\end{array}$ & \\
\hline & $\mathrm{S}_{0} \rightarrow \mathrm{S}_{55}$ & 266.32 & 0.0836 & $\mathrm{HOMO}-5 \rightarrow \mathrm{LUMO}+5$ & 0.42068 & \\
\hline & $\mathrm{S}_{0} \rightarrow \mathrm{S}_{56}$ & 264.54 & 0.1094 & $\begin{array}{l}\mathrm{HOMO}-9 \rightarrow \mathrm{LUMO}+2 \\
\mathrm{HOMO}-8 \rightarrow \mathrm{LUMO}+2 \\
\mathrm{HOMO}-1 \rightarrow \mathrm{LUMO}+5\end{array}$ & $\begin{array}{l}0.48856 \\
-0.19242 \\
0.27865 \\
\end{array}$ & \\
\hline & $\mathrm{S}_{0} \rightarrow \mathrm{S}_{57}$ & 262.33 & 0.1716 & $\begin{array}{l}\mathrm{HOMO}-9 \rightarrow \mathrm{LUMO}+2 \\
\mathrm{HOMO}-5 \rightarrow \mathrm{LUMO}+5 \\
\mathrm{HOMO}-4 \rightarrow \mathrm{LUMO}+5 \\
\mathrm{HOMO}-2 \rightarrow \mathrm{LUMO}+5 \\
\mathrm{HOMO}-2 \rightarrow \mathrm{LUMO}+7 \\
\mathrm{HOMO}-1 \rightarrow \mathrm{LUMO}+5\end{array}$ & $\begin{array}{l}-0.24371 \\
-0.24091 \\
-0.25407 \\
0.20626 \\
0.30782 \\
0.32002\end{array}$ & \\
\hline \multirow{3}{*}{$m$-FIr } & $\mathrm{S}_{0} \rightarrow \mathrm{S}_{1}$ & 462.95 & 0.0263 & $\mathrm{HOMO} \rightarrow \mathrm{LUMO}$ & 0.70166 & \\
\hline & $\mathrm{S}_{0} \rightarrow \mathrm{S}_{6}$ & 393.55 & 0.0423 & $\begin{array}{c}\mathrm{HOMO}-2 \rightarrow \mathrm{LUMO} \\
\mathrm{HOMO}-2 \rightarrow \mathrm{LUMO}+1 \\
\mathrm{HOMO}-1 \rightarrow \mathrm{LUMO}+1\end{array}$ & $\begin{array}{l}-0.41398 \\
0.42182 \\
0.31148 \\
\end{array}$ & \\
\hline & $\mathrm{S}_{0} \rightarrow \mathrm{S}_{53}$ & 267.06 & 0.3060 & $\begin{array}{c}\mathrm{HOMO}-8 \rightarrow \mathrm{LUMO}+2 \\
\mathrm{HOMO} \rightarrow \mathrm{LUMO}+7\end{array}$ & $\begin{array}{l}-0.24031 \\
0.25154\end{array}$ & \\
\hline \multirow{3}{*}{$p$-FIr } & $\mathrm{S}_{0} \rightarrow \mathrm{S}_{1}$ & 463.29 & 0.0286 & $\mathrm{HOMO} \rightarrow \mathrm{LUMO}$ & 0.70148 & \\
\hline & $\mathrm{S}_{0} \rightarrow \mathrm{S}_{8}$ & 388.02 & 0.0581 & $\begin{array}{c}\mathrm{HOMO}-1 \rightarrow \mathrm{LUMO}+1 \\
\mathrm{HOMO} \rightarrow \mathrm{LUMO}+3\end{array}$ & $\begin{array}{l}-0.43685 \\
0.47613 \\
\end{array}$ & \\
\hline & $\mathrm{S}_{0} \rightarrow \mathrm{S}_{52}$ & 271.08 & 0.2512 & $\begin{array}{c}\mathrm{HOMO}-7 \rightarrow \mathrm{LUMO}+4 \\
\mathrm{HOMO}-3 \rightarrow \mathrm{LUMO}+5 \\
\mathrm{HOMO}-2 \rightarrow \mathrm{LUMO}+5 \\
\mathrm{HOMO} \rightarrow \mathrm{LUMO}+7\end{array}$ & $\begin{array}{l}-0.27219 \\
0.21898 \\
0.29024 \\
-0.21723\end{array}$ & \\
\hline
\end{tabular}

Table 2 also shows the lowest-lying absorption peak of $o$-FIr, $m$-FIr, and $p$-FIr at 463.87, 462.95, and $463.29 \mathrm{~nm}$, respectively, which is dominantly responsible for the excitation of HOMO $\rightarrow$ LUMO. Table S2 shows that the HOMO of $o$-FIr, $m$-FIr, and $p$-FIr is composed of $50.1 \% \operatorname{Ir}(\mathrm{d})+47.7 \% \pi\left(\mathrm{N}^{\wedge} \mathrm{O}+\right.$ $\left.\mathrm{N}^{\wedge} \mathrm{C}\right), 50.3 \% \operatorname{Ir}(\mathrm{d})+47.9 \% \pi\left(\mathrm{N}^{\wedge} \mathrm{O}+\mathrm{N}^{\wedge} \mathrm{C}\right), 48.6 \% \operatorname{Ir}(\mathrm{d})+49.3 \% \pi\left(\mathrm{N}^{\wedge} \mathrm{O}+\mathrm{N}^{\wedge} \mathrm{C}\right)$, respectively, while their LUMOs are contributed by ca. $80 \% \pi^{*}\left(\mathrm{~N}^{\wedge} \mathrm{C}\right)$. Thus, the lowest-lying absorptions of these complexes originate from the $\left[\operatorname{Ir}(\mathrm{d})+\pi\left(\mathrm{N}^{\wedge} \mathrm{O}+\mathrm{N}^{\wedge} \mathrm{C}\right)\right] \rightarrow \pi^{*}\left(\mathrm{~N}^{\wedge} \mathrm{C}\right)$ excited state with MLCT/ILCT/LLCT character. The mount of MLCT of the lowest-lying absorption of $o$-FIr, $m$-FIr, and $p$-FIr is ca.22\%, which is similar to that of FIrpic. Furthermore, as shown in Figure 4, the absorption intensity of $\mathrm{N}\left(\mathrm{CH}_{3}\right)_{2}$-substituted Ir complexes ( $m$-FIr, $o$-FIr, $p$-FIr) in the highest energy absorption spectra have been effectively enhanced, which may increase the intersystem crossing rates (ISC). For $o$-FIr, the highest energy absorption peak 
$(262.33 \mathrm{~nm})$ is contributed by the mixture excitations of $\mathrm{HOMO}-9 \rightarrow \mathrm{LUMO}+2, \mathrm{HOMO}-5 \rightarrow \mathrm{LUMO}$ $+5, \mathrm{HOMO}-4 \rightarrow \mathrm{LUMO}+5, \mathrm{HOMO}-2 \rightarrow \mathrm{LUMO}+5, \mathrm{HOMO}-1 \rightarrow \mathrm{LUMO}+5$. Since the $\mathrm{Ir}(\mathrm{d})$ in the $\mathrm{HOMO}-9, \mathrm{HOMO}-4, \mathrm{HOMO}$ is $22.7 \%, 67.5 \%, 50.1 \%$, respectively, the MLCT contributed $8.9 \%$ to the $262.33 \mathrm{~nm}$ of $o$-FIr, which is slightly larger than that of FIrpic. For $m$-FIr and $p$-FIr, the absorption peak with large oscillator strength is located at 267.06 (attributed by HOMO $-8 \rightarrow$ LUMO +2 and $\mathrm{HOMO} \rightarrow \mathrm{LUMO}+7$ ) and $271.08 \mathrm{~nm}$ (attributed by $\mathrm{HOMO}-7 \rightarrow \mathrm{LUMO}+4, \mathrm{HOMO}-$ $3 \rightarrow \mathrm{LUMO}+5, \mathrm{HOMO}-2 \rightarrow \mathrm{LUMO}+5, \mathrm{HOMO} \rightarrow \mathrm{LUMO}+7)$, respectively. Combining the transition configuration with the orbital composition, the mount of MLCT of the high energy absorption peaks for $m$-FIr and $p$-FIr are only $4.4 \%$ and $5.2 \%$, respectively. Clearly, the contribution of MLCT in the whole absorption spectra of $o$-FIr are remarkably larger than those of FIrpic, $m$-FIr, and $p$-FIr. Normally, the participation of MLCT in the absorption spectra is a critical factor affecting the intensity of the singlet-triplet transitions, and thus improves the quantum efficiency. Thus, the calculated results indicate that the introduction of $\mathrm{N}\left(\mathrm{CH}_{3}\right)_{2}$ groups at the ortho-position of $\mathrm{N}^{\wedge} \mathrm{O}$ ligand is useful to enhance the intersystem crossing and singlet-triplet transitions, and therefore the possibility of the phosphorescent quantum yield might be enhanced.



Figure 4. Simulated absorption spectra of studied complexes with the data calculated at the TD-M06L level.

\subsection{Phosphorescence Emission Spectra}

Based on the optimized lowest triplet excited state $\left(T_{1}\right)$ geometries, vertical $T_{1}-S_{0}$ transition energies $\left(\Delta \mathrm{E}_{\mathrm{vert}}\right)$ and the emission wavelength $(\mathrm{nm})$ obtained by CAMB3LYP functional are collected in Table 3, together with available experimental values [24]. Since the vertical $\mathrm{T}_{1}-\mathrm{S}_{0}$ transition energy $\left(\Delta \mathrm{E}_{\mathrm{vert}}\right)$ is the electronic energy difference between the $\mathrm{T}_{1}$ and $\mathrm{S}_{0}$ state at the optimized $\mathrm{T}_{1}$ geometry, it is therefore strongly dependent on the functional. The molecular orbital compositions responsible for the emission spectra of the studied complex are given in Table S3. The $0-0 T_{1} \rightarrow S_{0}$ transition energy $\left(\Delta E_{0-0}\right)$ is calculated by the energy difference between the $S_{0}$ and $T_{1}$ states at their respective optimized geometries obtained by M06 functional.

As listed in Table 3, the calculated emission peak for FIrpic based on the calculated $E_{\mathrm{vert}}$ and $\mathrm{E}_{0-0}$ method is located at 490.49 and $480.86 \mathrm{~nm}$, respectively. The slightly longer wavelength derived from $E_{v e r t}$ is caused by only one single configuration, while real emission is composed of more than one configuration. The phosphorescence at $490.49 \mathrm{~nm}$ of FIrpic is contributed by the excitation of $\mathrm{HOMO} \rightarrow$ LUMO. According to the orbital composition analyses, the HOMO is contributed by $42.8 \%$ $\operatorname{Ir}(\mathrm{d})+54.3 \% \pi\left(\mathrm{C}^{\wedge} \mathrm{N}+\mathrm{N}^{\wedge} \mathrm{O}\right)$, while the LUMO is mainly focused on $\mathrm{C}^{\wedge} \mathrm{N}$ ligand. Accordingly, the emission of FIrpic can be attributed to ${ }^{3} \mathrm{MLCT} /{ }^{3} \mathrm{LLCT} /{ }^{3} \mathrm{ILCT}$ character. The $\mathrm{d}(\mathrm{Ir})$ orbital contributes to $42.8 \%$ for HOMO, and thus the emission of FIrpic at $490.49 \mathrm{~nm}$ has ${ }^{3} \mathrm{MLCT}(20.31 \%)$ transition character. For $\mathrm{N}\left(\mathrm{CH}_{3}\right)_{2}$-substituted Ir complexes, the phosphorescent emissions based on $\mathrm{E}_{\mathrm{vert}}$ method are located at 492.78, 484.32, and $485.83 \mathrm{~nm}$ for 0 -FIr, $m$-FIr, and $p$-FIr, respectively, which is dominantly responsible for excitations of $\mathrm{HOMO} \rightarrow \mathrm{LUMO}$ and $\mathrm{HOMO}-4 \rightarrow \mathrm{LUMO}$. This is because the HOMO 
and HOMO -4 of $o$-FIr, $m$-FIr, and $p$-FIr are mainly contributed by $\mathrm{d}(\operatorname{Ir})$ and $\pi\left(\mathrm{C}^{\wedge} \mathrm{N}+\mathrm{N}^{\wedge} \mathrm{O}\right)$ (besides the HOMO -4 of $m$-FIr), while the LUMOs of $o$-FIr and $m$-FIr are located at $\pi^{*}\left(\mathrm{C}^{\wedge} \mathrm{N}\right)$. Table 3 shows that the calculated $\mathrm{E}_{0-0}$ for these designed complexes are ca. $480 \mathrm{~nm}$. Accordingly, these designed complexes have similar phosphorescent emissions and transition character with that of FIrpic, which might be a potential candidate for blue-emitting materials. Furthermore, the $\mathrm{d}(\mathrm{Ir})$ orbital contributions to $\mathrm{HOMO}$ and HOMO $-4(42.8 \%$ and $0.97 \%$ for $m$-FIr, $30.68 \%$ and $36.68 \%$ for $p$-FIr $)$ are much smaller than that of HOMO $(41.35 \%)$ and HOMO $-4(63.39 \%)$ for $o$-FIr. The larger d(Ir) orbital composition results in slightly larger ${ }^{3} \mathrm{MLCT} \%$ in its phosphorescence of $o$-FIr $(18.78 \%)$ than $m$-FIr $(9.11 \%)$ and $p$-FIr $(11.56 \%)$. Therefore, the $o$-FIr may have improved $\Phi_{\mathrm{p}}$ compared with $m$-FIr and $p$-FIr.

Table 3. The calculated phosphorescence emission wavelength $(\mathrm{nm})$, along with metal-ligand charge transfer character $\left({ }^{3} \mathrm{MLCT}, \%\right)$ and available experimental values.

\begin{tabular}{|c|c|c|c|c|c|c|c|}
\hline \multirow{2}{*}{ Molecule } & \multicolumn{4}{|c|}{$E_{\text {vert }}$} & \multicolumn{2}{|c|}{$E_{0-0}$} & \multirow{2}{*}{$\frac{\operatorname{Exp}[24]}{\lambda(\mathrm{nm})}$} \\
\hline & $\lambda(\mathrm{nm})$ & $\mathrm{E}(\mathrm{eV})$ & Composition & ${ }^{3}$ MLCT (\%) & $\lambda(\mathrm{nm})$ & $\mathrm{E}(\mathrm{eV})$ & \\
\hline FIrpic & 490.49 & 2.53 & $0.49(\mathrm{HOMO} \rightarrow \mathrm{LUMO})$ & 20.31 & 480.86 & 2.58 & 468 \\
\hline$o$-FIr & 492.78 & 2.52 & $\begin{array}{c}0.45 \begin{array}{c}(\mathrm{HOMO}-4 \rightarrow \mathrm{LUMO}) \\
(\mathrm{HOMO} \rightarrow \mathrm{LUMO})\end{array} \\
\end{array}$ & 18.78 & 482.58 & 2.60 & \\
\hline$m$-FIr & 484.32 & 2.56 & $\begin{array}{c}-0.36(\mathrm{HOMO}-4 \rightarrow \mathrm{LUMO}) \\
(\mathrm{HOMO} \rightarrow \mathrm{LUMO})\end{array}$ & 9.11 & 481.78 & 2.57 & \\
\hline$p$-FIr & 485.83 & 2.55 & $\begin{array}{c}-0.36(\mathrm{HOMO}-4 \rightarrow \mathrm{LUMO}) 0.49 \\
(\mathrm{HOMO} \rightarrow \mathrm{LUMO})\end{array}$ & 11.56 & 481.76 & 2.57 & \\
\hline
\end{tabular}

To give some insight into the nonradiative rate constant $\left(\mathrm{k}_{\mathrm{nr}}\right)$, the high lying metal-centered $\left({ }^{3} \mathrm{MC} \mathrm{d}-\mathrm{d}\right)$ excited states of studied complexes-which is one of the most important deactivation pathways for the phosphoresce emission from $\mathrm{T}_{1}$ in transition-metal complexes-were optimized by unrestricted M06L method. The energy difference between ${ }^{3} \mathrm{MLCT} / \pi-\pi^{*}$ and ${ }^{3} \mathrm{MC} \mathrm{d}-\mathrm{d}$ excited states are drawn in Figure 5, along with the spin density distribution in the ${ }^{3} \mathrm{MC} d-\mathrm{d}$ state. As shown in Figure 5, the ${ }^{3} \mathrm{MC}$ d-d state of studied complexes are lying at a relatively higher energy than that of ${ }^{3} \mathrm{MLCT} / \pi-\pi^{*}$ state, which suggests that the possibility of a radiationless pathway is low. Furthermore, the energy difference between the ${ }^{3} \mathrm{MLCT} / \pi-\pi^{*}$ and ${ }^{3} \mathrm{MC} \mathrm{d}$-d excited states of $o$-FIr $(0.30 \mathrm{eV})$ and $m$-FIr $(0.30 \mathrm{eV})$ is larger than that of FIrpic $(0.24 \mathrm{eV})$. Therefore, these calculation results show that ortho- and meta- substituted Ir complexes are useful to decrease the $\mathrm{K}_{\mathrm{nr}}$. Based on the above viewpoint, it becomes clear that introducing the $\mathrm{N}\left(\mathrm{CH}_{3}\right)_{2}$ at the ortho-position of $\mathrm{N}^{\wedge} \mathrm{O}$ ligand in FIrpic led to larger ISC and $\mathrm{k}_{\mathrm{r}}$ values, as well as the smaller $\mathrm{k}_{\mathrm{nr}}$ value relative to others. Therefore, $o$-FIr is considered to be used as potential blue-emitting emits with high quantum efficiency.

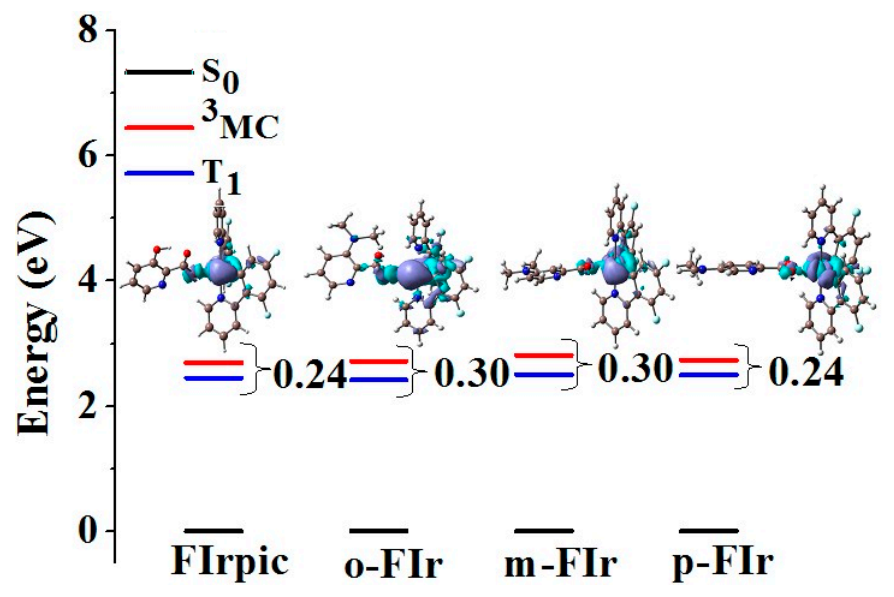

Figure 5. Energy level diagram of the studied complexes in the $\mathrm{T}_{1}$ and triplet metal centered $\left({ }^{3} \mathrm{MC}\right)$ excited states, together with the contour plots of the spin density distribution in the ${ }^{3} \mathrm{MC}$ state. 


\subsection{Performance in OLEDs}

To evaluate the performance of OLED devices, it is highly important to investigate the charge injection and transfer ability. The ionization potential (IP) and electron affinity (EA) are usually employed to evaluate the energy barrier for the hole and electron injections. Normally, the lower IP (larger EA) value suggests that it is easier to inject hole (electron). According to the Marcus theory [25], the electron transfer rate constants can be expressed by the following formula:

$$
k=\left(\frac{\pi}{\lambda k_{B} T}\right)^{1 / 2} \frac{V^{2}}{\hbar} \exp \left(-\frac{\lambda}{4 k_{B} T}\right)
$$

where $T$ and $k_{B}$ is the temperature and Boltzmann constant, respectively. The $\lambda$ is the reorganization energy, and V is the coupling matrix element. According to Equation (1), the intermolecular charge transfer rate $\mathrm{k}$ is determined by two factors, $\lambda$ and $\mathrm{V}$. Due to the limited intermolecular charge transfer range in the solid state, the mobility of charges has been demonstrated to be primarily associated with the reorganization energy $\lambda$ for OLED materials [26]. The detailed description of the calculations of vertical ionization potential $(\mathrm{IP}(\mathrm{v}))$, vertical electron affinity $(\mathrm{EA}(\mathrm{v}))$, hole extraction potential, $(\mathrm{HEP})$, electron extraction potential (EEP) and electron reorganization energy $\left(\lambda_{\text {electron}}\right)$, as well as hole reorganization energy $\left(\lambda_{\text {hole }}\right)$ are listed in our previous report [16]. According to the previous report [16], the IP, EA, and $\lambda$ of studied complexes are calculated and listed in Table 4.

Table 4. The calculated ionization potential (IP, eV), electron affinities (EA, eV), hole extraction potential, $(\mathrm{HEP}, \mathrm{eV})$, electron extraction potential $(\mathrm{EEP}, \mathrm{eV})$ hole/electron reorganization energy $\left(\lambda_{\text {hole }} / \lambda_{\text {electron, }} \mathrm{eV}\right)$.

\begin{tabular}{ccccccc}
\hline Molecule & IP(v) & HEP & EA(v) & EEP & $\lambda_{\text {hole }}$ & $\boldsymbol{\lambda}_{\text {electron }}$ \\
\hline FIrpic & 6.56 & 6.29 & 0.72 & 0.98 & 0.27 & 0.26 \\
$o$-FIr & 6.32 & 6.06 & 0.48 & 0.69 & 0.26 & 0.21 \\
$m$-FIr & 6.39 & 6.09 & 0.56 & 0.75 & 0.30 & 0.19 \\
$p$-FIr & 6.34 & 6.11 & 0.53 & 0.73 & 0.23 & 0.20 \\
\hline
\end{tabular}

Compared with FIrpic, all these designed complexes have smaller IP(v) and HEP, which is consistent with their higher HOMO energy levels. Thus, the hole injection ability of these designed complexes are improved by introduction of dimethylamine substitutions at the $\mathrm{C}^{\wedge} \mathrm{O}$ ligand. However, $o$-FIr, $m$-FIr, and $p$-FIr have smaller EA values than FIrpic, which will lead to worse electron injection ability compared with FIrpic. According to Equation (1), the $\lambda$ is required to be small for efficient charge transport. As listed in Table 4, the $\lambda_{\text {electron }}$ of studied complexes are slightly smaller than that of FIrpic, indicating that these complexes have excellent electron transfer ability. The difference between

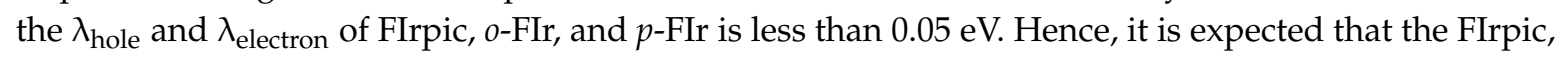
$o$-FIr, and $p$-FIr might have excellent charge transfer balance, which is one of the key factors affecting the performance of OLEDs.

\section{Computational Details}

The geometrical structures of the ground state $\left(\mathrm{S}_{0}\right)$ of FIrpic were fully optimized by B3LYP $[27,28]$, CAMB3LYP [29], M06L [30], and mPW1PW91 [31] methods, respectively, combined with 6-31G(d) basis set for the non-metal atoms $(\mathrm{H}, \mathrm{C}, \mathrm{N}, \mathrm{O}$, and $\mathrm{F})$ and a "double-j" quality basis set LANL2DZ for Ir atom. The calculated vibrational frequencies with no imaginary frequencies based on the optimized geometries verify that each of the optimized structures was a true minimum on the potential energy surface. The calculated results are collected in Table S1 in the supporting information, together with the crystal data [21]. As depicted in Table S1, the bond lengths obtained for B3LYP and CAMBLYP overestimated the bond lengths, especially Ir- $\mathrm{N}_{1}(0.024 \AA$ for CAMB3LYP and $0.031 \AA$ for B3LYP) and Ir- $\mathrm{N}_{3}(0.049 \AA$ for CAMB3LYP and $0.073 \AA$ for B3LYP), while the bond length differences between the calculated results obtained by M06L and crystal data were small. Therefore, the ground-state 
geometries of the studied complexes were calculated by M06L method. Based on the ground-optimized structure, the vertical excitation energies were calculated by TD-M06L method with continuum polarizable continuum model (CPCM). The lowest-lying triplet excited state geometries $\left(\mathrm{T}_{1}\right)$ and triplet-centered ( $\left.{ }^{3} \mathrm{MC}\right) \mathrm{d}-\mathrm{d}$ states were optimized by unrestricted M06L method. Based on the $\mathrm{T}_{1}$ equilibrium geometries, four different functionals-PBE0, B3LYP, CAMB3LYP, and M06L-were performed on the emission spectra calculations (as listed in Table S4). The CAMB3LYP functional was adopted to predict the emission spectra of these complexes, because the calculated results obtained by CAMB3LYP were consistent with the experimental results. All calculations were performed with the Gaussian 09 software package [32].

\section{Conclusions}

In this work, the geometrical and electronic structures, absorption and emission spectra, as well as phosphorescence efficiencies for a series of dimethylamine-substituted iridium(III) complexes FIrpic have been investigated by density functional theory (DFT) and time-dependent density functional theory (TDDFT) methods. The results indicate that the introduction of dimethylamine is useful to extend the $\pi$-electron delocalization, increase HOMO energy levels, and enhance hole injection and transfer ability. Furthermore, the absorption intensity and participation of MLCT of these dimethylamine substitutions are significantly stronger than that of FIrpic, suggesting the possibility of singlet-to-triplet transitions are enhanced, and therefore the phosphorescent quantum yield might be increased by introducing dimethylamine. Importantly, through the analyses of triplet energy $\left(\mathrm{E}_{\mathrm{T} 1}\right)$, participation of ${ }^{3} \mathrm{MLCT}$ in phosphorescent spectra, as well as the energy difference between the ${ }^{3} \mathrm{MLCT} / \pi-\pi$ and ${ }^{3} \mathrm{MC} \mathrm{d}-\mathrm{d}$ state, it can be inferred that $o$-FIr has larger $\mathrm{k}_{\mathrm{r}}$ values and smaller $\mathrm{k}_{\mathrm{nr}}$ values compared with other molecules. So, the strategy of introducing the dimethylamine in $\mathrm{N}^{\wedge} \mathrm{O}$ ligand of FIrpic should be useful in the design of more-efficient blue emitters.

Supplementary Materials: Supplementary materials are available on line.

Acknowledgments: Financial supports from the Fundamental Research Funds for the Central Universities (No. 2015XKMS042). We are grateful to the High Performance Computing Center of China University of Mining and Technology for the award of CPU hours to accomplish this work.

Author Contributions: Hong-Qu Tang performed the calculation work; Guo-Jun Kang and Xue-Feng Ren analyzed the data and wrote the manuscript.

Conflicts of Interest: The authors declare no conflict of interest.

\section{References}

1. $\quad$ Lin, C.-H.; Chiu, Y.-C.; Chi, Y.; Tao, Y.-T.; Liao, L.-S.; Tseng, M.-R.; Lee, G.-H. Mechanistic Investigation of Improved Syntheses of Iridium(III)-Based OLED Phosphors. Organometallics 2012, 31, 4349-4355. [CrossRef]

2. Xia, H.; Zhu, Y.; Lu, D.; Li, M.; Zhang, C.; Yang, B.; Ma, Y. Ruthenium(II) Complexes with the Mixed Ligands 2,2'-Bipyridine and 4,4'-Dialkyl Ester-2,2'-bipyridine as Pure Red Dopants for a Single-Layer Electrophosphorescent Device. J. Phys. Chem. 2006, 110, 18718-18723. [CrossRef] [PubMed]

3. Zhang, T.-T.; Jia, J.-F.; Ren, Y.; Wu, H.-S. Ligand Effects on Structures and Spectroscopic Properties of Pyridine-2-aldoxime Complexes of $\operatorname{Re}(\mathrm{CO})^{3+}$ : DFT/TDDFT Theoretical Studies. J. Phys. Chem. 2011, 115, 3174-3181. [CrossRef] [PubMed]

4. Ho, C.-L.; Wong, W.-Y. Small-molecular blue phosphorescent dyes for organic light-emitting devices. New J. Chem. 2013, 37, 1665-1683. [CrossRef]

5. Won, D.-I.; Lee, J.-S.; Ji, J.-M.; Jung, W.-J.; Son, H.-J.; Pac, C.; Kang, S.O. Highly Robust Hybrid Photocatalyst for Carbon Dioxide Reduction: Tuning and Optimization of Catalytic Activities of Dye/ $\mathrm{TiO}_{2} / \mathrm{Re}(\mathrm{I})$ Organic-Inorganic Ternary Systems. J. Am. Chem. Soc. 2015, 137, 13679-13690. [CrossRef] [PubMed]

6. Lamansky, S.; Djurovich, P.; Murphy, D.; Abdel-Razzaq, F.; Lee, H.-E.; Adachi, C.; Burrows, P.E.; Forrest, S.R.; Thompson, M.E. Highly Phosphorescent Bis-Cyclometalated Iridium Complexes: Synthesis, Photophysical Characterization, and Use in Organic Light Emitting Diodes. J. Am. Chem. Soc. 2001, 123, 4304-4312. [CrossRef] [PubMed] 
7. Velmurugan, G.; Ramamoorthi, B.K.; Venuvanalingam, P. Are Re(I) phenanthroline complexes suitable candidates for OLEDs? Answers from DFT and TD-DFT investigations. Phys. Chem. Chem. Phys. 2014, 16, 21157-21171. [CrossRef] [PubMed]

8. Rausch, A.F.; Thompson, M.E.; Yersin, H. Matrix Effects on the Triplet State of the OLED Emitter Ir(4,6-dFppy)2(pic) (FIrpic): Investigations by High-Resolution Optical Spectroscopy. Inorg. Chem. 2009, 48, 1928-1937. [CrossRef] [PubMed]

9. Kozhevnikov, V.N.; Zheng, Y.H.; Clough, M.; Al-Attar, H.A.; Griffiths, G.C.; Abdullah, K.; Raisys, S.; Jankus, V.; Bryce, M.R.; Monkman, A.P. Cyclometalated Ir(III) Complexes for High-Efficiency Solution-Processable Blue PhOLEDs. Chem. Mater. 2013, 25, 2352-2358. [CrossRef]

10. Rausch, A.F.; Thompson, M.E.; Yersin, H. Blue Light Emitting Ir(III) Compounds for OLEDs - New Insights into Ancillary Ligand Effects on the Emitting Triplet State. J. Phys. Chem. 2009, 113, 5927-5932. [CrossRef] [PubMed]

11. Sajoto, T.; Djurovich, P.I.; Tamayo, A.B.; Oxgaard, J.; Goddard, W.A.; Thompson, M.E. Temperature Dependence of Blue Phosphorescent Cyclometalated Ir(III) Complexes. J. Am. Chem. Soc. 2009, 131, 9813-9822. [CrossRef] [PubMed]

12. Yi, S.; Kim, J.-H.; Cho, Y.-J.; Lee, J.; Choi, T.-S.; Cho, D.W.; Pac, C.; Han, W.-S.; Son, H.-J.; Kang, S.O. Stable Blue Phosphorescence Iridium(III) Cyclometalated Complexes Prompted by Intramolecular Hydrogen Bond in Ancillary Ligand. Inorg. Chem 2016, 55, 3324-3331. [CrossRef] [PubMed]

13. Stringer, B.D.; Quan, L.M.; Barnard, P.J.; Wilson, D.J.D.; Hogan, C.F. Iridium Complexes of N-Heterocyclic Carbene Ligands: Investigation into the Energetic Requirements for Efficient Electrogenerated Chemiluminescence. Organometallics 2014, 33, 4860-4872. [CrossRef]

14. Chu, W.-K.; Yiu, S.-M.; Ko, C.-C. Neutral Luminescent Bis(bipyridyl) Osmium(II) Complexes with Improved Phosphorescent Properties. Organometallics 2014, 33, 6771-6777. [CrossRef]

15. You, Y.; Park, S.Y. Phosphorescent iridium(III) complexes: toward high phosphorescence quantum efficiency through ligand control. Dalton Trans. 2009, 1269, 1267-1282. [CrossRef]

16. Kang, G.J.; Ren, X.F.; He, Q.Q. Theoretical study on effect of thiophene substitution on the structure and phosphorescence quantum yields of red-emitting iridium(III) emitters in OLEDs. J. Photochem. Photobiol. 2016, 319, 25-33. [CrossRef]

17. Shang, X.H.; Han, D.M.; Zhou, D.F.; Zhang, G. Shedding light on the photophysical properties of iridium(III) complexes with a dicyclometalated phosphate ligand via N-substitution from a theoretical viewpoint. New J. Chem. 2017, 41, 1645-1652. [CrossRef]

18. Baranoff, E.; Curchod, B.F.E.; Monti, F.; Steimer, F.; Accorsi, G.; Tavernelli, I.; Rothlisberger, U.; Scopelliti, R.; Grätzel, M.; Nazeeruddin, M.K. Influence of Halogen Atoms on a Homologous Series of Bis-Cyclometalated Iridium(III) Complexes. Inorg. Chem. 2012, 51, 799-811. [CrossRef] [PubMed]

19. Lee, S.; Kim, S.-O.; Shin, H.; Yun, H.-J.; Yang, K.; Kwon, S.-K.; Kim, J.-J.; Kim, Y.-H. Deep-Blue Phosphorescence from Perfluoro Carbonyl-Substituted Iridium Complexes. J. Am. Chem. Soc. 2013, 135, 14321-14328. [CrossRef] [PubMed]

20. Li, J.; Zhang, Q.; He, H.; Wang, L.; Zhang, J. Tuning the electronic and phosphorescence properties of blue-emitting iridium(III) complexes through different cyclometalated ligand substituents: A theoretical investigation. Dalton Trans. 2015, 44, 8577-8589. [CrossRef] [PubMed]

21. Xu, M.-L.; Che, G.-B.; Li, X.-Y.; Xiao, Q. Bis[3,5-difluoro-2-(2-pyridyl)phenyl]-(picolinato)iridium(III). Acta Cryst. 2009, E65, m28. [CrossRef] [PubMed]

22. Wen, Y.; Liu, Y. You have full text access to this content, Recent Progress in n-Channel Organic Thin-Film Transistors. Adv. Mater. 2010, 22, 1331-1345. [CrossRef] [PubMed]

23. Zhang, S.-F.; Chen, X.-K.; Fan, J.-X.; Ren, A.-M. Charge transport properties in a series of five-ring-fused thienoacenes: A quantum chemistry and molecular mechanic study. Org. Electron. 2013, 14, 607-620. [CrossRef]

24. Baranoff, E.; Curchod, B.F.E. FIrpic: Archetypal blue phosphorescent emitter for Electroluminescence. Dalton Trans. 2015, 44, 8318-8329. [CrossRef] [PubMed]

25. Lin, B.C.; Cheng, C.P.; Lao, Z.P.M. Reorganization Energies in the Transports of Holes and Electrons in Organic Amines in Organic Electroluminescence Studied by Density Functional Theory. J. Phys. Chem. 2003, 107, 5241-5251. [CrossRef] 
26. Marcus, R.A. On the Theory of Oxidation-Reduction Reactions Involving Electron Transfer. J. Chem. Phys. 1956, 24, 966-978. [CrossRef]

27. Lee, C.; Yang, W.; Parr, R.G. Development of the Colle-Salvetti correlation-energy formula into a functional of the electron density. Phys. Rev. 1988, 37, 785-789. [CrossRef]

28. Becke, A.D. Density-functional thermochemistry. III. The role of exact exchange. J. Chem. Phys. 1993, 98, 5648-5652. [CrossRef]

29. Yanai, T.; Tew, D.P.; Handy, N.C. A new hybrid exchange-correlation functional using the Coulomb-attenuating method (CAM-B3LYP). Chem. Phys. Lett. 2004, 393, 51-57. [CrossRef]

30. Zhao, Y.; Truhlar, D.G. A new local density functional for main-group thermochemistry, transition metal bonding, thermochemical kinetics, and noncovalent interactions. J. Chem. Phys. 2006, 125, 194101-194118. [CrossRef] [PubMed]

31. Adamo, C.; Barone, V. Exchange functionals with improved long-range behavior and adiabatic connection methods without adjustable parameters: The mPW and mPW1PW models. J. Chem. Phys. 1998, 108, 664-675. [CrossRef]

32. Frisch, M.J.; Trucks, G.W.; Schlegel, H.B.; Scuseria, G.E.; Robb, M.A.; Cheeseman, J.R.; Scalmani, G.; Barone, V.; Mennucci, B.; Petersson, G.A.; et al. Gaussian 09; Revision B.04; Gaussian: Wallingford, CT, USA, 2009.

Sample Availability: Sample Availability: Not available.

(C) 2017 by the authors. Licensee MDPI, Basel, Switzerland. This article is an open access article distributed under the terms and conditions of the Creative Commons Attribution (CC BY) license (http:/ / creativecommons.org/licenses/by/4.0/). 